\title{
Drugs, Pleasure, Sexuality and the Australian Space in Christos Tsiolkas' Loaded and Kate Holden's In My Skin
}

\author{
Anna Dunkley
}

\section{Abstract}

This paper draws on theories regarding the connection between pleasure and space in illicit drug use, and investigates the Australian socio-cultural understanding of this connection through a close reading of illicit drug use in Christos Tsiolkas' novel, Loaded, and Kate Holden's memoir In My Skin. This combination of texts - which illustrate the experiences of a gay youth and a prostitute set in the same Australian urban space in approximately the same period - also illuminates the ways in which illicit drug use is often understood as gendered and sexualised, as performed as such. Ultimately, this paper draws on the two texts to provide a greater understanding of the linkages between gender, sexuality, pleasure, spatial context and illicit drug use.

\section{Introduction}

The aching longing to be somewhere else, out of this city, out of this country, out of this body and out of this life ${ }^{1}$.

Illicit drug use, along with its associated harms, pleasures and social ramifications, is an essentially contested issue, and often clouded by folklore, pseudo-scientific hypotheses and ill-informed political policy. One thing, however, is clear: drugs are not taken in a vacuum, and the pleasures associated with drug use are not only obtained through isolated psychological and physiological reactions. Rather, aspects of the context in which drugs are consumed can affect and enhance the experience of drug-related pleasure for individuals. Hence, this essay will explore the relation between illicit drug-related pleasure and context, specifically spatial context, to further understandings of the complexities of illicit drug use ${ }^{2}$.

Christos Tsiolkas. Loaded. (Sydney: Vintage Random House, 1995) 19.

2 Please note that this paper will be discussing the ramifications of illicit drug use, and not legal medications. 
While the first section will involve a brief overview of a scientific hypothesis surrounding the significance of space in the experience of drug use, the main focus of this essay will be the socio-cultural understandings of this connection; therefore, the second, third and fourth sections of this essay will largely draw on the fields of addiction studies and human geography, as well as two works of creative writing, to present a picture of drug-related pleasure and space. This diversity of disciplinary frameworks provides greater understanding and breadth, indeed, Thrift applauds the "work currently being undertaken as a result of alliances between social sciences and artists" ${ }^{\prime 3}$ as creatively uniting both theoretical and practical knowledge.

The combination of Christos Tsiolkas' novel, Loaded, and Kate Holden's memoir In My Skin is complementary. While the authors employ aspects of autobiography and set their stories in the same city, they illustrate different experiences of the connection between drug-related pleasure, space, and sexuality. The elements of autobiography infuse the texts with authenticity, suggesting to readers that aspects of the experiences of the characters are grounded in reality. By basing their work on personal experience the authors are able to write with credibility about their own perspectives on drug-taking, space and sexuality, reiterating the particularity of drug-use. Similarly, both Holden and Tsiolkas set their stories in Melbourne, at approximately the same period - late 1980s until the early 2000s - and portray the city so vividly that it almost becomes a character. Tsiolkas even divides Loaded into sections corresponding to the four regions of Melbourne: East, North, South, and West. Despite locating their stories in the same city, the texts depict quite different experiences of drug-use. Tsiolkas' novel explores a young gay man's experience with 'recreational' drugs, while Holden highlights a very different experience of heroin use as a prostitute. Tsiolkas' protagonist Ari emphasises this divide, declaring "they're on heroin, I'm on speed, different drugs, different moods." ${ }^{4}$ These differences underline the importance of the varying interactions between space, sexuality, identity and drug choice.

This essay will firstly provide a brief outline of the scientific hypothesis which presents evidence for the connection between space and drug-related pleasure. This will be followed by an exploration of the notions of 'intensive' and 'affective' space, and how these concepts are illustrated by Tsiolkas and Holden. The third section will explore how the texts show the links between drug use, the performance of sexuality, and space. Finally, the fourth section of this essay will illustrate how drug users can imagine spaces as an entrapment, an escape, or, sometimes, both simultaneously. Ultimately, the experience of using drugs

3 Nigel Thrift, 'Intensities of feeling: towards a spatial politics of affect'. Geografiska Annaler: Series B, Human Geography, Vol. 86, No. 1, Special Issue: The Political Challenge of Relational Space 57-78. (2004) 75.

4 Christos Tsiolkas, Loaded, 77. 
is not limited to the purely physiological effect on the body, but encompasses a diverse range of factors, particularly including the corporeal context of space. To begin with, it is important to clarify what is meant by the general term 'space'. According to Thrift, space can be understood as relational, thus, "rather than space being viewed as a container within which the world proceeds, space is seen as a co-product of those proceedings." ${ }^{5}$ Space, therefore, can be understood as being comprised not only of the physical structures and objects in a location, and its landscape, but of networks of movement and interactions, weather, sounds, smells, and the 'feel' or 'vibe' of the area as experienced by individuals, amongst other aspects. Thus, as de Certeau argues, "space is a practiced place" ${ }^{6}{ }^{6}$

\section{Section One: Science}

Both scientific studies and social science concur that there is a connection between the experience of drug-related pleasure and space. The article by Trevor Robbins and Barry Everitt outlines the hypothesis that

drug-seeking behaviour can become powerfully associated with environmental cues, which, as 'conditioned stimuli', predict... the availability of drugs (and their associated hedonistic effects). ${ }^{7}$

This process is described as one of 'associative learning', in which the drug user connects these environmental cues, such as particular spaces, with the pleasures involved in their drug use. Thus, entering or re-visiting a space in which one has previously used drugs may act as a conditioned stimulus, and "activate the specific neural network that consolidated the original memory, through a series of plastic neuronal changes", ${ }^{8}$ even without actually using drugs on that occasion. Thus, re-visiting such a site may evoke some of the sensory effects or patterns of behaviour associated with taking the drug, despite the absence of the actual drug on this later occasion, which may have implications for individuals attempting to curb their drug usage.

\footnotetext{
5 Nigel Thrift, 'Space: The fundamental stuff of human geography' in S. Holloway, S. Rice and G. Valentine (eds). Key Concepts in Geography (London: Sage Publications, 2004) 96.

6 Michel de Certeau, The Practice of Everyday Life. trans. Steven Rendall, (Berkerly: University of California Press, 1984) 117.

7 Trevor W. Robbins, and Barry J. Everitt, 'Drug addiction: bad habits add up' Nature. Vol. 398, 567-570. (April 1999) 569.

8 Ibid. 569.
} 


\section{Section Two: Affective Spaces}

The previous section briefly outlined the process of associative learning which causes individuals to connect their experiences of drug taking and pleasure with particular spaces, and this section adds to this by arguing that this is at least partially due to the 'affective' and 'intensive' natures of such spaces. Thrift focuses on the notion of 'affect', and its role in shaping experiences of urban environments. The term 'affect' can be broadly understood as a kind of force of emotion, of joy or anger or alienation, which works upon people, however, he stresses that it is "non-individual... an impersonal force". ${ }^{9}$ He imagines 'affect' to take the form of a "'transhuman' framework in which individuals are generally understood as effects of the events" 10 to which their bodies respond. Thus, as Thrift highlights, space is an important factor in the production of affects as it has an inherently expressive quality. ${ }^{11}$ Therefore, the many, complex aspects of which space is comprised - including built forms, objects, music and noise, decoration and lighting - all contribute to the 'vibe' of that space, and this affects individuals and shapes their experiences. Duff draws on this idea of affective space to argue that the pleasures linked to drug use encompass the "corporeal experience of space". ${ }^{12}$ Zinberg also influenced Duff's argument, by outlining the idea of the importance of 'set' and 'setting' in the experience of drug taking. ${ }^{13}$ Furthermore, Thornton suggests that rave culture moved away from traditional venues into "new sites like disused warehouses, aircraft hangars, municipal pools and tents in farmers' fields... partly in pursuit of forbidden and unpredictable senses of place." ${ }^{\prime 14}$ This search reflects Duff's suggestion that the spatial contexts of drug use shape experiences to the extent that different sensory and psychological effects are felt depending on the location in which drugs are consumed. ${ }^{15}$ Moreover, individuals can be aware of being positioned and influenced by affective spaces, and, as Duff argues, drug use should therefore be viewed as a "heterogeneous assemblage of risks, conscious and unconscious choices and decisions, physical and psychical sensations, affects, corporeal processes, structural and contextual forces" ${ }^{\prime 16}$

Both of the novels portray affective spaces, and Loaded in particular shows how some individuals take drugs to enhance the experience of their surroundings. For example, Ari uses many illicit, 'recreational' drugs, which are often taken

9 Nigel Thrift, 'Space: The fundamental stuff of human geography' 104.

10 Nigel Thrift, 'Intensities of feeling: towards a spatial politics of affect'. (2004) 60 .

11 Nigel Thrift, 'Space: The fundamental stuff of human geography' 104.

12 Cameron Duff, 'The Pleasure in Context'. International Journal of Drug Policy 19 (2008) 384.

13 N. Zinberg, Drug, set, setting: the basis for controlled intoxicant use. (Yale: Yale University Press, 1984).

14 Fiona. Measham. 'Play space: historical and socio-cultural reflections on drugs, licensed leisure locations, commercialisations and control'. International Journal of Drug Policy Vol. 15 (2004).

15 Cameron Duff, 'The pleasure in context'. 386.

16 Ibid. 385. 
to intensify activities such as dancing and sexual acts in recreational spaces such as clubs and pubs. ${ }^{17}$ Ari's connection between the drug 'speed' and the Greek term kefi - "the urge to dance, to be with good friends, to open your arms to life"18 - reveals one of the motivations for his drug use: to enhance his experience of clubbing. As Duff highlights, the pleasure associated with drugs can be "deeply embedded in specific contexts and specific places, like clubs, bars, private homes and open spaces", ${ }^{19}$ and Tsiolkas' depiction of 'grounded' drug use matches this. Ari, for example, 'blasts' (injects) speed at the home of his dealer, though he doesn't often inject drugs because it makes him "apprehensive". ${ }^{20}$ However, at his dealer's house he does inject, ostensibly because he feels lethargic, yet it seems that the choice is also influenced by the space's atmosphere, which is conducive to that form of behaviour because it is inhabited by "smackheads". ${ }^{21}$ There are more subtle aspects of difference swirling throughout the space, such as reggae music, incense, cigarette and dope smoke, and conversations about opium dens in Kashmir. All of these aspects affect Ari, and the unusual, intensive scene makes his unaccustomed mode of drug use seem more permissible.

Tsiolkas thus explores the potential for drugs to enhance the experience of a space, frequently using detailed language to evoke sensuous details of sounds, smells, and sights, to highlight the sensual spaces in which he sets his scenes. For example, he writes that Ari perceives that the "speed accentuates the lights and colours of the street... the air seems to hum from the electricity". ${ }^{22}$ This short line perhaps encapsulates the notion of 'intensive' space, which, according to the philosopher Manual DeLanda, is 'felt' profoundly. He distinguishes between 'extensive' space, which involves the basic understanding of space as comprising of three geometric dimensions, and 'intensive' space, which incorporates the potential for spaces to exude affect, and thus is more meaningfully perceived as possessing a particular energy or 'vibe'. ${ }^{23}$ This 'vibe' is comprised of the whole of the space, including physical forms, lighting, music, and the people interacting and moving within that space. Thus, Ari links the sense of community within a club to its music, and the physical effects of the array of drugs he has taken:

Noise connects with the pleasure emanating from my gut... LSD, the ecstasy, the speed, the dope, the alcohol rush around my body and I feel one with the pulsating crowd... ${ }^{24}$

17 Ibid. 387.

18 Christos Tsiolkas, Loaded. 23.

19 Duff, Cameron. op. cit. 388.

20 Christos Tsiolkas, Loaded. 21

21 Ibid. 20.

22 Ibid. 33.

23 Cameron Duff, op. cit. 388 cites philosopher Manual DeLanda's (2005, 80-83).

24 Christos Tsiolkas, Loaded. 94. 
Thus, as Duff suggests, the use of drugs offers individuals a means of 'tapping into' this vibe, amplifying existing feelings of closeness and connection. ${ }^{25}$ of course, as Thrift emphasises, the affective power of spaces is not 'natural', rather, urban environments are consciously designed by humans intent on producing particular responses, through their knowledge of strategies such as event management, logistics, music, performance, lighting, urban and interior design. ${ }^{26}$ Thus, the pubs and clubs that Ari attends reflect efforts to engineer the atmosphere of enjoyment and excessive consumption.

In contrast, throughout the majority of her memoirs Holden does not depict her drug use as predominately driven by the desire to enhance her experience of a pre-existing situation, though on she writes that on one occasion "it was a sunny day, and I felt cheerful; some smack would make everything sparkle just that little more" ${ }^{27}$ Her use of drugs differs drastically to Ari's, as his kind of 'recreational' drugs are accepted by both his peers, and Holden, as acceptable, while heroin is seen as "radiating transgression" ${ }^{28}$ This sense of difference extends to the way in which it is considered in connection with space, as she suggests that "heroin insulates against sensation" ${ }^{29}$ and thus the experience of space. Moreover, Holden eventually uses the drug, not because she wants to, but rather because she becomes unable to stop; indeed, she writes that "the drug took me out of the house, on cold bleak nights, on aching feet; it drove me to places I didn't want to be". ${ }^{30}$ Thus, Holden's experience of drugs is linked to space, but not necessarily positively, indeed, she shows how individuals can be compelled to enter into unappealing spaces. Ultimately, Holden is generally less focused on enhancing pre-existing pleasure through drug use, and more concerned with preventing the pain of withdrawal.

Nonetheless, her memoirs do illustrate the affective power of intensive spaces to a certain extent, particularly in her descriptions of the pleasures and dangers inherent in 'scoring' heroin in inner city Melbourne. She highlights the heightened atmosphere of the area, the "bustle of that street just before midnight", 31 and suggests that it seemed like a space separate from the others she moved in, a "different scene", 32 which enabled her to enact a different persona in pursuit of a deal. The various expressive elements of the space, such as the blue lights of the bar's bathrooms, and the strident sounds of the amusement parlours on the street and their "clashing lights and bells and yelling boys"

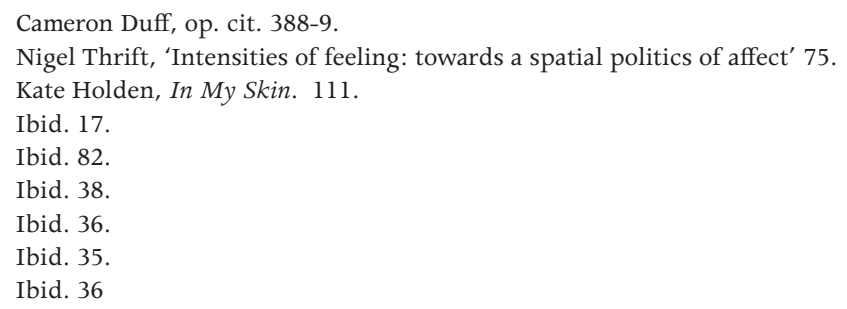


enhanced her sense that the space was a "surreal" 34 sphere separate from the normal daylight world. Moving through this space in the city, she performs the role of the aggressive, "swaggering junkie". ${ }^{35}$ The academics Dovey and Fitzgerald have studied the often contradictory feelings of safety and danger for drug users in public spaces, and they discuss the common sense of a 'buzz' of exhilaration surrounding such spaces known to be used by drug dealers. One of the heroin-users that they interviewed, for instance, responded "...I don't know a junkie who doesn't love scoring off the street...there's always this bit of a thrill of anticipation..."36 This reinforces Holden's personal account of enjoying the sense of danger and power in the dark streets of inner city Melbourne. This combination of pleasurable thrills in potentially dangerous spaces reoccurs throughout much of both the creative or personal accounts of heroin use, and the academic work done surrounding this drug use. For example, Dovey and Fitzgerald examine in great detail a section of Smith Street in Melbourne, and the way in which liminal or periphery zones are often used for injecting, including laneways, car parks, public toilets, in an effort to shield illegal drug use from the attention of the authorities. ${ }^{37}$ However, as Holden realises at one stage in her memoirs, this kind of seclusion and isolation can simultaneously protect the drug user from legal ramifications, yet also be dangerous for them in the case of an overdose of the drug. Holden calculates the balance of pleasure, safety and danger when deciding where to use heroin, writing

I looked around the drab cream walls of the room, the peeling carpet, the harsh dense light from the lamp suspended above... I thought, quite soberly, if I have it here, then when I fall I'll be visible from the hall. Someone passing might see me. Someone might save me. ${ }^{38}$

Thus, there can be a desirable, pleasurable risk inherent in such intensive spaces, which is enhanced by drug use, just as the pleasures associated with drugs are amplified by the space in which they are taken.

\section{Section Three: Sexuality}

This section will explore the links between sexuality, drug use, and space, as sexuality is the dominant reason that Ari and Kate use drugs. Holden demonstrates the connection between female sexuality and drugs by showing how Kate begins using drugs to maintain her sexual relationship, and then starts 
to 'sell sex' to maintain her dependency. Kate's movement from her family home, to the streets, and then to brothels is largely due to drug use, and shapes her sex work. Ari also consumes drugs to enhance his sexual experiences, which take place in liminal spaces outside his traditional Greek-Australian household. By using drugs and moving beyond the physical bounds of his suburb, Ari attempts to find a space in which he can enact an identity which accommodates both his homosexuality and ethnicity.

Thus, through his endless movement across the city, Ari seeks freedom, particularly the sexual freedom he feels is denied by his culture and home life. He declares "home is the last place I want to be", 39 and revels in the liberty of liminal spaces in the city, finding joy through drug use and sexual interactions "in bedrooms, toilets, cars, under railway bridges, on the beach, in strange lounge rooms, in the back row of porn cinemas". ${ }^{40}$ Like Kate, Ari's enjoyment is partly rooted in the sensation of exhilarating risk and pleasurable potential danger. For example, when he leaves the security of the familiar Greek pub The Retreat with a stranger, Ari immediately notices the difference in his surroundings, as the cheerful "mass of people and noise"41 gives way to the dark car park and then alleyway, where the "smells of beer mix with the stench of garbage". ${ }^{42}$ This change of location, the shift in scents, sounds and company is more than merely a physical movement of a few metres, and it affects Ari profoundly. He becomes suddenly conscious of the potential danger of entering a secluded alleyway at night with a stranger, hesitates, thinking "of those crazy men who get off on death", 43 thereby highlighting the link between pleasure and the notion of destruction. Yet, he is not deterred, and walks "into the dark landscape of a dream" 44 in search of sexual pleasure, buoyed by his drug intake, which exaggerates and enhances his libido. Tsiolkas makes clear the connection between Ari's use of drugs, his corporeal experience of bodily sensations, and his drive to experience sexual gratification, writing:

The drugs are circulating through my body. My skin is alive in sharp bursts of electricity. My nipples are erect, my face is flushed, the hair on my naked arms tingling. I'll have to dance soon, or fuck soon. The energy inside me is pushing against the confines of my body. ${ }^{45}$

Once sated, at least temporarily, Ari smokes a cigarette and tosses it away, "mixing the tobacco in with the come and piss on the ground". ${ }^{46}$ This graphic

39 Christos Tsiolkas, Loaded. 112.

40 Ibid. 108.

41 Ibid. 53.

42 Ibid.57.

43 Ibid. 57.

44 Ibid. 58.

45 Ibid. 54.

46 Ibid. 59 
image visually represents the way in which his use of substances such as nicotine, alcohol and illicit drugs are irrevocably intertwined with his broader experience of the landscape that surrounds him, and his sexuality. Fitzgerald and Threadgold explore this notion of intermingling bodily fluids with the shared space of the city, arguing that this represents "something profound", ${ }^{47}$ a kind of unifying of the individual and the universal. Ari, almost certainly, would abhor this idealism.

Tsiolkas makes it clear that Ari is aware, to a certain extent, of the way in which his sexuality is a performance shaped by the space that surrounds him. For example, when in The Retreat, he is vividly conscious of the atmosphere of sensuality, the "availability of sex", 48 noting that "everyone in this place wants to be seen, to be admired", 49 and this heightens his own desire. This is further exaggerated in the inner city. In the club, the drug use and search for sexual partners is more pronounced, and the two are shown to be inseparable:

Drugs mould the club, drugs initiate the dancing, the search for sex... Without the drugs the music would be numbing, monotonous. Without the drugs the faces would be less attractive... ${ }^{50}$

This also hints at the notion that communities can be formed and fuelled by shared drug taking, which Holden refers to as "the bonhomie of complicity". ${ }^{51}$ Duff describes the idea that "the various clubs, bars and venues that make up Melbourne's night-time economy support vast, loosely integrated affective networks", 52 and Slavin furthers this by imagining a kind of "tribal space" that can be shaped by shared drug use. Tsiolkas, however, is ultimately despairing about the possibility for such comradeship; indeed, near the end of the novel Ari denies the validity of friendships founded in shared drug and alcohol use, saying that "none of this connection between us is real, it is all hallucinations". ${ }^{54}$ This is illustrated by the way that Ari and George fail to properly connect, despite their mutual attraction. Throughout the novel they exchange cigarettes and joints, passing them from one to the other as a proxy for verbal communication. Yet, while this shared drug use enables them to establish ties of giving and receiving, and sharing pleasure, Ari is determined to maintain

\footnotetext{
47 Fitzgerald and Threadgold 'Fear of sense in the street heroin market' International Journal of Drug Policy 15 407-417. (2004).

48 Christos Tsiolkas, Loaded. 54.

49 Ibid. 54.

50 Ibid. 89

51 Kate Holden, In My Skin. 24.

52 Cameron Duff, 'The drifting city: the role of affect and repair in the development of 'Enabling Environments' International Journal of Drug Policy 20: 3 202-8. (2009).

53 Sean Slavin. 'Drugs, space, and sociality in a gay nightclub in Sydney'. Journal of Contemporary Ethnography, (2004 266).

54 Christos Tsiolkas, Loaded. 141.
} 
his performance of his identity a young, non-feminised gay man, so he cannot properly communicate his feelings for George. This paradox is encapsulated in the lines:

I must appear strong for him to want me. He too wants the one hundred percent genuine wog fuck... [but] I want to tell him I adore him. ${ }^{55}$

Ari's adherence to the code of sexual desire results in his enactment of "a wog boy, a straight boy" ${ }^{\prime \prime 6}$ in an effort to attract George, yet this very performance, and lack of tenderness and honesty, drives him away.

Holden depicts a different experience of drug taking, which nonetheless irrevocably intertwines drug use and sexuality with space, firstly as a metaphor for love, and later as a movement through physical spaces to exchange sexual services for drug money. She initially imagines drug use as a metaphoric space, a different 'world', and thus, she begins to use heroin to follow her boyfriend to "a strange place I didn't know". ${ }^{57}$ She envisages her boyfriend and their drug using friends as "people who had crossed a river, who were going somewhere joyously while I stood alone on the other bank". ${ }^{58}$ Holden's text explores the way that drugs became an intrinsic part of her romantic relationships, shaping their sensuality and sense of love. For example, one of her motivations for beginning to use heroin was the promise of potential pleasure, and she imagines her boyfriend "sinking backwards on a bed in the ecstasy of a smack rush, with an almost erotic charge of horror". ${ }^{59}$ Further, the actual process of drug taking initially involves a heightened sense of intimacy:

with junk in our veins, we were the most beautiful people in the world... the sex was fantastic... now we couldn't stop talking, touching... ${ }^{60}$

Thus, Holden illustrates how heroin was originally a way of enhancing their shared sexuality, and describes how they declared their love "every time we slid the needle into the other's arm". ${ }^{61}$ Yet, with more frequent use, this dynamic changed as their relationship faltered: "when we scored, we were full of love... when we didn't, there was silence" ${ }^{\prime 6}{ }^{62}$

Thus, Holden increased her use of heroin, and eventually began to work as a prostitute to fund both her own drug habit, and that of her boyfriend,

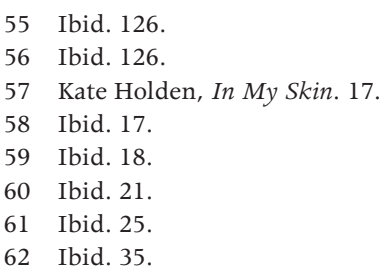


highlighting the disturbingly prevalent link between sex work and drug use. ${ }^{63}$ According to studies done by Wellisch et al this pattern of dyadic relationships is common in the heroin using community. ${ }^{64}$ Of course, the link between selling sex and drug use goes both ways; indeed, while studies by Boyd et al in 2000 acknowledge the many women who become prostitutes to fund their drug use, they focus predominately on the high instance of female prostitutes who begin using drugs after becoming prostitutes. ${ }^{65}$ Sex, for Holden, became "a currency", ${ }^{66}$ and once again, like Ari, the liminal spaces of the city were the areas in which both her sexual interactions and drug use took place. In their study of the connection between prostitution and illicit drug use Cusick and Martin highlight the significance of this "shared environmental space on the streets". ${ }^{67}$ Holden describes her search for discreet spaces, such as "cul-desacs, canal-sides, back lanes, the parking spots of empty office blocks" ${ }^{\prime 68}$ and laneways, reiterating the notion that both illicit sexual interactions and drug use are pushed to the peripheries of society. Holden highlights the bleakness of working on the streets, the dangers of being arrested by the police, or molested by aggressive individuals, and the grimness of Melbourne winter weather at night. She also illustrates the isolation of her lifestyle, underlining the divide between the space of the streets and private dwellings, writing "I stood in the dark on the footpath and gazed in on bright living rooms" ${ }^{69}$

Holden, however, shows that by moving to a brothel she began to close this divide, as "compared to the streets... [the brothel] was comfort itself". ${ }^{70}$ She depicts the physical details of the brothels in great detail, noting the differences between these spaces and the street, and suggests that these differences altered the atmosphere and the behaviour of the people who move through them. Thus, privacy of the tasteful, comfortable lounge rooms and bedrooms, low lighting, the warmth, the quiet and the "clean ambience"71 created an environment of greater formality than the streets, ${ }^{72}$ and, therefore, she "felt more performative". ${ }^{73}$ Accordingly, the men also behaved differently, and they

\footnotetext{
63 C. Sterk, and K. Elifson, 'Drug-Related Violence and Street Prostitution' in Drugs and Violence: Causes, Correlates, and Consequences, a part of the National Institute on Drug Abuse Research Monograph Series. Number 103.(1990) 212.

64 D. Wellisch, and G. Gay, and R McEntree, 'The Easy Rider Syndrome: A Pattern of Hetero- and Homosexual Relationships in a Heroin Addict Population' Family Process Volume 9, Issue 4, pages 425-430 (December: 1970).

65 C. Boyd, A. Young, and A. Hubbell, 'Prostitution, Drug Use, and Coping with Psychological Distress' Journal of Drug Issues 30: 4, 789-800. (2000) 1.

66 Kate Holden, In My Skin. 104.

67 Linda, Cuisick, and Anthea Martin, “Vulnerability and involvement in drug use and sex work'. Home Office Research Study 268. 3. http://rds.homeoffice.gov.uk/rds/pdfs04/hors268.pdf

68 Kate Holden, In My Skin. 91.

69 Ibid. 2.

70 Ibid. 127.

71 Ibid. 121.

72 Ibid. 120

73 Ibid. 120.
} 
shared a "stagy intimacy"74 that was absent in the streets. Other factors such as the presence of security, administration, and facilities for showering also change their behaviour. Indeed, the status of individuals, and the amount that they charge, depends largely on the space in which they work, even though they offer similar services whether they work on the streets, cheap motels or brothels. $^{75}$

Moreover, because in brothels female sexuality is classed as a commodity, the performance of femininity is a particularly important part of business; however, Holden illustrates how it became a point of professional and personal pride to be the best, the most attractive, the most skilled sex worker. She describes how she "constructed"76 Lucy - her prostitute persona - with lingerie, dresses and makeup. She "became a creature of glittery eyes, brilliant red lips and smooth velvet", ${ }^{77}$ and saw the decadent dresses as "costumes, my armour: my becoming... I put them on and became a woman". ${ }^{78}$ While Holden suggests that her self-esteem grew in these spaces, throughout the narrative it is clear that her work serves as a means to an end: heroin. The portrayal of prostitution as positive is undermined by the stark line: "I would need all the girly wiles I'd disdained my entire life if I were to make the money I needed", ${ }^{79}$ and thus, readers are reminded of the commercial connection between drugs and sexuality. Both Holden and Tsiolkas portray characters who are very different, yet whose performances of sexuality are nevertheless intertwined with their drug use, and the varying spaces they inhabit.

\section{Section Four: Escape}

This section will explore the notion of drugs and 'escape', firstly by examining Ari's attempts to use drugs to escape the dreariness and alienation of his life, and secondly in terms of physically moving to escape drug addiction, as Kate does. Throughout Loaded, Ari rejects his home, his culture and his parents, and longs to "be somewhere else, out of this city, out of this country, out of this body and out of this life". ${ }^{80}$ While in the East of Melbourne, Ari notices the suburban landscape:

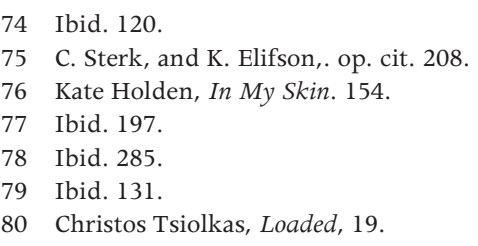


every street around here looks like every other street, every stranger you meet walking along looks like the same stranger you passed blocks ago... East, west, south, north, the city of Melbourne blurs into itself... ${ }^{81}$

He uses drugs to keep him "quiet... and relatively content", 82 and the general description of why some individuals use drugs seems to fit Ari exactly: "some young people turn to drugs as a means of dulling, or escaping from, awareness of their lack of ability to find meaningful ways to participate in society" ${ }^{83}$ Thus, Ari tries to use drugs to transcend, rather than fit into the landscape that surrounds him, and this is illustrated by his joy as he drives with his friends into the city "grinning from ear to ear... watching the suburbs drop away" ${ }^{84}$ Melechi writes that this use of drugs and partying as an escape is prevalent, describing the tendency of 'clubbing culture' to attempt to disappear into the dark spaces of cities, the areas which both embody and "represent a fantasy of liberation, an escape from identity. A place where nobody is, but everybody belongs" ${ }^{85}$

Yet, even being in the city, using drugs, only offers him momentary freedom, and so he is always on the move, and refers to himself as a runner, "running away from a thousand and one things that people say you have to be". ${ }^{86}$ As Schwarz notes, this quote demonstrates how Ari connects the spatial performance of the body, his movement across the city, and his identity. ${ }^{87}$ Moreover, Tsiolkas depicts Ari aspiring to escape physically in two ways, firstly, Ari speaks vaguely of going to Greece, and "meeting new people, getting excited about unfamiliar sights, sounds, and smells... a couple of years away from the family and all their hang-ups and expectations". ${ }^{88}$ Yet, while Ari dreams of "new places, new faces, new lives possible to live at the other side of the world", ${ }^{89}$ the grasping protectiveness of his family, and his refusal to get a job, keep him stationary. The second way in which he aspires to permanently escape is through loving George, and this too is imagined as a physical movement into another space, separate from the suburbs which he detests so much. He dreams of "a little house by the sea with George and me in it", ${ }^{90}$ yet he refuses to tell George that he loves him, and thus, this avenue is also abandoned. On the first page of

\footnotetext{
81 Ibid. 37-38.

82 Ibid.146.

83 Mark Peyrot, 'Institutional and Organizational Dynamics in Community-Based Drug Abuse Treatment'. Social Problems Vol. 38. No. 1 20-33. (Feb 1991) on page 20-21 cites Kolton, Dosher, and Dwarshuis (1972: 335).

84 Christos Tsiolkas, Loaded. 48.

85 Fiona Measham. op. cit.

86 Christos Tsiolkas, Loaded. 149.

87 Anja Schwarz, 'Mapping (Un)Australian Identities: 'Territorial Disputes' in Christos Tsiolkas' Loaded' pages 13-2 in Bartels, Anke, and Wiemann, Dirk. (eds) Global Fragments: (dis)orientation in the new world order (New York, 2007) 20.

88 Christos Tsiolkas, Loaded. 27.

89 Ibid. 13.

90 Ibid 146.
} 
Loaded, Ari alerts the reader to the fact that he is staying at his brother's share house by saying "it's not my place". ${ }^{91}$ By the end of the novel, Tsiolkas leaves readers doubtful whether or not Ari will ever escape this alienation to find a place of his own.

Holden writes of a different kind of escape: a physical move into a new space to escape from drug use back into 'normal' life. In an interview, she spoke of the notion of "doing a geographical". ${ }^{92}$ This concept, according to Holden, was an important one in the drug using community, and centres on the idea that drug use is tied to physical space, and so, if one can get out of the drug 'scene', then they will be able to stop using drugs more easily. Cusick and Martin reiterate this idea, but expand it to include sex work as well, and support it with empirical evidence. Thus, they argue that

Successful treatment for drug use in the case of these sex workers was strongly linked to residential separation from the drug selling markets that share pavement space with sex markets. ${ }^{93}$

This reflects the way in which individuals can be aware of their 'associative learning' and connection between space and drug use. Holden exemplifies this by asserting that she did not dwell on drugs while at work, however "once home, the idea was automatic", ${ }^{94}$ thereby highlighting how she had unintentionally conditioned herself to associate drug use with a particular spatial context. Further, when she attempts to break her heroin habit, Holden goes to a rehabilitation clinic, which is, importantly, "sealed from the outside world". ${ }^{95}$ She describes in some depth her behaviour at the centre, highlighting her eventual happiness, energy and self-confidence, and noting "how different we felt inside here", ${ }^{96}$ thereby stressing the perception of a dichotomy between the secure, drug-free 'inside', and the outside world of the city. This is only underlined when she goes immediately to her dealer after leaving the centre. "Out of the safe environment," Holden writes, "I felt like I'd walked out of a dream", ${ }^{97}$ and this illustrates how entrenched her patterns of behaviour in the city were. Similarly, when she travels to the countryside, she can stop using heroin, however, once she returns, she begins using again.

91 Ibid. 2

92 Interview with Kate Holden. Radio National 9:30am 'Life Matters' 11th October 2010.

93 Linda Cuisick, and Anthea Martin. op. cit. page vii. http://rds.homeoffice.gov.uk/rds/pdfs04/hors268.pdf

94 Kate Holden, In My Skin. 245.

95 Ibid. 48.

96 Kate Holden, In My Skin. 245.

97 Ibid. 55 . 
This romanticisation of the country as a drug-free zone of health and simplicity (in stark opposition to the city) is echoed by Chalmers, who argued that it is impossible "not to think of heroin and the needle in terms of the city... in connection with the intensification of urbanity". ${ }^{98}$

Similarly, Holden twice returns to her parents' house to try and escape her addiction, in a move which was simultaneously symbolic, and practical. This is encapsulated in the line "the flat was too full of memories, and Jake [her dealer] was just across the road". ${ }^{99}$ Thus, Holden highlights the seductive attraction of the knowledge that drugs are easily available in certain places, and also the power of the memory of past pleasures. Further:

away from the claustrophobia of my little house... I felt removed from my recent history... The grimness of housing commission flats and dull drugs seemed so very far away... ${ }^{100}$

Her parents' house is, significantly, her childhood home, and therefore evocative of her previous, non drug-using identity and past behaviour. She again imagines space as both physical, and metaphorical, writing that "it was like a return to one's own country to be at my parents"". ${ }^{101}$ While she does use heroin at her family home, she managed to mostly maintain her performance of the "nice polite, middle-class girl living with her parents in an old haven of innocence" ${ }^{102}$ Yet, when she left the security of her family home, she was conscious of a change in her behaviour, thus, "in the city, I was a swaggering junkie in dark streets". ${ }^{103}$ It is not until she combines living at her parents' with the goal of travelling to Europe that Holden manages to finish her methadone program and escape her addiction. By idealising her move overseas as a "glowing portal on the horizon ahead", ${ }^{104}$ and leaving the drug-saturated city, Kate manages to escape her destructive heroin use, even though, when she returns to St Kilda, "the place is a palimpsest of memories"105 and temptations for her, even now.

\section{Conclusion}

This essay has argued that the gratification associated with illicit drug use includes those pleasures connected to the space in which the drugs are

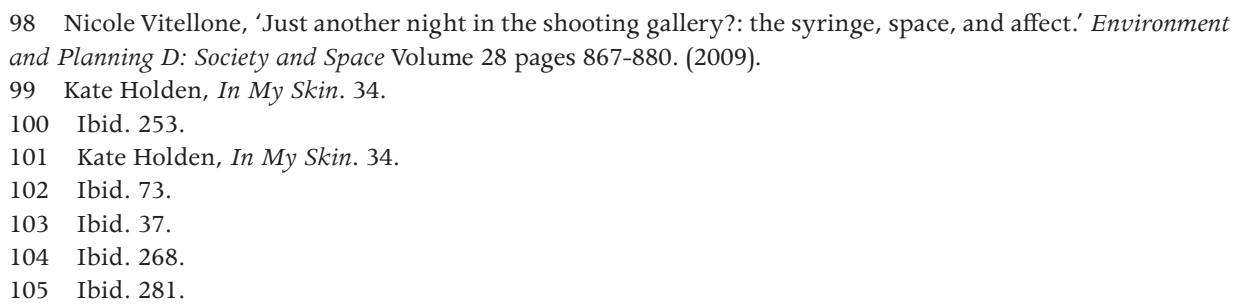


consumed. While, according to Vitellone, this method of understanding drug use in connection with its spatial context is a relatively new one, ${ }^{106}$ context is clearly a vital part of drug use, and this is reflected by Loaded and In My Skin. Drugs are not consumed in a vacuum, and the consumption of drugs is inherently linked to physical context due to its inherently corporeal nature. Hence, this essay has explored the pleasures associated with spatial context and drugs, examining theories of associative learning, and affective and intensive spaces. Further, the way that performances of sexuality are linked to drug use and space have been outlined, by exploring the fictionalised experiences of Kate and Ari. These characters have been shown to embody hopes for escape, though Ari is apparently unable to leave the city and its repressive socio-cultural notions of manhood. Conversely, Kate manages to escape her dependency, but temptation remains in the spaces in which she once consumed drugs. 